\title{
Age-associated developmental changes in the activated partial thromboplastin time (APTT) and causes of prolonged APTT values in healthy Chinese children
}

\author{
Jianxin $\mathrm{Li}^{1,2}$, Xin $\mathrm{Lai}^{2}$, Cunliang Yan², Anping \\ $\mathrm{Xu}^{2}$, Liping $\mathrm{Nie}^{2}$, Yu Zhou ${ }^{2}$, Chaoyu Liao ${ }^{2}$ \\ and Hanyun Ren ${ }^{1, *}$ \\ ${ }^{1}$ Department of Hematology, Peking University First \\ Hospital, Beijing, P.R. China \\ ${ }^{2}$ Department of Laboratory Medicine, Peking \\ University Shenzhen Hospital, Shenzhen, P.R. China
}

\section{Abstract}

Background: The concept of developmental hemostasis has been universally accepted. Physiological reference ranges for coagulation tests are available for infants and children of different ages. However, on Oriental children they are rare.

Methods: Results of preoperative activated partial thromboplastin time (APTT) in neonates, infants, children aged 1-18 years and adults with minor elective surgery in a university affiliated hospital were reviewed retrospectively. Plasma activity of factors VIII, IX, XI, XII (FVIII:C, FIX:C, FXI:C, FXII:C) and lupus anticoagulants (LAC) in 47 children with prolonged APTT and 34 adult controls were measured to investigate the causes of prolongation.

Results: Compared with adults, APTT values were prolonged significantly and were age-dependent in children, especially in neonates and infants aged 1-6 months. Mean values for FXII:C and FIX:C in children with prolonged APTT values were significantly lower than those in adults $(p<0.001)$. Prolonged APTT values correlated negatively with FXII:C and FIX:C, and weakly with the LAC Screen ratio (LAC-SR) $\left(r_{0.01}=\right.$ $-0.808,-0.705$ and $0.372, p=0.000,0.000$ and 0.001 , respectively). There was weak negative correlation between FXII:C and LAC-SR $\left(r_{0.01}=-0.277, p=0.012\right)$. No significant correlation was seen between prolonged APTT values and FVIII:C or FXI:C.

Conclusions: APTT values change dynamically with age during childhood and display a distinct pattern of evolution in children. Lower values of FXII:C and $\mathrm{FIX}: \mathrm{C}$, and presence of LAC contribute to the prolongation of APTT values in Chinese children. Clin Chem Lab Med 2009;47:1531-7.

Keywords: activated partial thromboplastin time; blood coagulation factor; developmental hemostasis; lupus anticoagulants.

\footnotetext{
*Corresponding author: Prof. Hanyun Ren, MD, PhD, Department of Hematology, Peking University First Hospital, No. 8, Xishiku Street, Beijing, 100034, China Phone: +86-10-66551122-5082, Fax: +86-10-66551811, E-mail: renhy0813@163.com

Received June 18, 2009; accepted August 25, 2009; previously published online November 2, 2009
}

\section{Introduction}

The concept of developmental hemostasis introduced by Andrew et al. (1-3) in the late 1980s has been universally accepted (4). The hemostatic system of children is significantly different from that in adults. Thus, an understanding of developmental hemostasis and the development of appropriate age-dependent reference ranges are pivotal for prevention, diagnosis, and treatment of hemostatic problems during childhood (4-7). Physiological reference ranges are available for premature infants, full-term infants and children from 1 to 16 years of age (1-9). However, most reports are relevant to Caucasians (1-9), while studies on developmental hemostasis in Oriental children is rare.

Differences exist in the hemostatic system between different racial/ethnic groups. For example, the incidence and risk of venous thromboembolism (VTE) is markedly lower in Asian/Pacific Islanders than in Caucasians and African Americans (10-14). VTE is not as common in Chinese as in Caucasians (15). Genetic risk factors related to VTE in Caucasians such as factor V Leiden and prothrombin G20210A mutations are rare in Asian, especially in Chinese and Japanese (16-22). The mean plasma concentrations of factors VII, VIII and fibrinogen were lower in Japanese than in Caucasians (23). In the MESA study, Chinese participants had among the highest concentrations of plasminogen activator inhibitor-1, but among the lowest of all other hemostatic factors and endothelial markers (24). The allele frequency of frequently occurring $\mathrm{C}-\mathrm{-}>\mathrm{T}$ polymorphism in the factor XII promoter region at nucleotide (nt) 46 is higher in Orientals than in Caucasians and Europeans $(25,26)$. This results in lower plasma factor XII activity in Orientals $(25,27)$. These differences stress the importance and necessity for establishing reference ranges for clotting assays related to race.

The activated partial thromboplastin time (APTT) is the most widely used test for identifying abnormalities in the intrinsic and common coagulation pathways, monitoring anticoagulant therapy with unfractionated heparin, and the detection of inhibitors of coagulation, the most common of which is the lupus anticoagulants (LAC) (28). Shortened APTT values may be associated with hypercoagulability and appear to be significantly associated with increased risk of VTE (28). There have been several reports concerning age-associated APTT values in healthy children, in which inconsistent conclusions were drawn with respect to values seen in adults $(4,6,29-31)$. It is recommended that coagulation laboratories devel- 
op age-related reference ranges specific to their own testing systems for the local population $(4,7,32)$. In this study, we reviewed retrospectively age-associated evolvement of APTT values in healthy Chinese subjects from birth through childhood. We also investigated prospectively the causes of longer APTT values in healthy children compared with adults.

\section{Materials and methods}

\section{Study population}

Preoperative coagulation data from children aged $0-18$ years receiving minor elective surgery in Peking University Shenzhen Hospital, from May 2004 to October 2007 was collected from the hospital information system and patient medical record and reviewed. The hospital is located in Shenzhen, where $>80 \%$ of the population migrated from other parts of China. Ethical approval was not required in this study, as preoperative coagulation tests including APTT, prothrombin time and platelet count were routinely performed in accordance with document No. (2000) 412 enacted by the Ministry of Health of the P.R. China. To qualify for the study, enrolled subjects had to meet the following criteria: no family history of bleeding or thrombophilia, no history of easy bruising, no history of heart, lung, liver or kidney diseases, normal physical examination, a normal white blood cell count, and no history of medication use for at least two weeks prior to specimen collection. All enrolled healthy neonates and infants from ages 1 to 6 months were full-term, did not experience any perinatal problems, and had no pathological jaundice, infection or malnutrition. Specimens with inappropriate ratio of blood to anticoagulant or hemolysis were excluded from analysis. Individuals who were shown by other laboratory examinations to have diseases affecting blood coagulation were also excluded. Preoperative coagulation examination data from adult control subjects were also reviewed. Subjects in the control group were patients receiving minor elective surgery during the same period. They had no history of hemorrhagic, thrombotic, cardiac, pulmonary, hepatic or renal diseases, and no history of taking medications for at least two weeks prior to collection of specimens.

\section{Laboratory analysis}

Blood samples ( $2 \mathrm{~mL}$ ) were obtained by venipuncture at the same time that routine blood for preoperative analysis was obtained. The blood was collected directly into a siliconized glass vacutainer (Improve Medical Instrument's Co, Ltd, Guangzhou, China) containing 3.2\% (109 mmol/L) buffered sodium citrate with a 9:1 ratio of blood to citrate. The specimens were centrifuged immediately at $2500 \mathrm{~g}$ for $15 \mathrm{~min}$ at room temperature to prepare platelet-poor plasma (PPP) for the preoperative coagulation screening tests. To investigate the causes of increased APTT values in children compared with adults, from March 2007 to October 2007, PPP from children with APTT values longer than $43.0 \mathrm{~s}$, the upper limit of the adult reference interval, and PPP from adult control subjects were collected immediately after the coagulation screening tests were completed. Samples were frozen at $-80^{\circ} \mathrm{C}$ until analysis of coagulation factors and LAC.

All coagulation assays were performed using the $\mathrm{ACL}$ Futura coagulation analyzer (Instrumentation Laboratory, Lexington, KY, USA) according to the manufacturer's specifications. For each assay, calibration was performed regularly and control samples measured daily. Coagulation screening tests were completed within $4 \mathrm{~h}$ following blood collection. APTT was measured using Lyophilized silica (HemosIL ${ }^{\mathrm{TM}}$, Milan, Italy) reagent. This reagent is sensitive to decreased concentrations of intrinsic factors and the presence of heparin anticoagulant. Results were measured in seconds with a clot-based method. Activity of coagulation factors VIII, IX, XI and XII (FVIII:C, FIX:C, FXI:C and FXII:C) were determined using one-stage clotting methods with respective factor-deficient plasma (HemosIL ${ }^{\mathrm{TM}}$, Milan, Italy) and the APTT reagent. LAC was assayed using LAC Screen/ LAC Confirm reagent (HemosIL ${ }^{T M}$, Milan, Italy), both of which were improved Diluted Russell's Viper Venom Test (DRVVT) reagents. The LAC Screen reagent is poor in phospholipid, making it sensitive to LAC. Specimens with a LAC Screen ratio (LAC-SR) above 1.2 were confirmed with LAC Confirm reagent, which is rich in phospholipid. Specimens with a normalized LAC ratio above 1.2 were considered to be LAC Confirm positive. The PPP was thawed and allowed to reach room temperature before coagulation factors and LAC were assayed in batch mode.

\section{Statistical analysis}

Statistical calculations were performed using SPSS version 17.0. Data are expressed as means with the 2.5 th-97.5th percentile in parentheses, or means $\pm 1 \mathrm{SD}$ (standard deviation). Non-parametric data were analyzed using the Kruskal-Wallis and Mann-Whitney U-tests. Comparison of the rate of two samples was performed using Fisher's exact probability test. Parametric data were analyzed using Student's t-test. Pearson correlation test was used for correlation.

\section{Results}

\section{Study population}

A total of 1466 infants and children met the enrollment criteria. Cases that were excluded included 66 cases with inappropriate ratio of blood to anticoagulant, 19 cases with specimen hemolysis, and three cases with increased values of serum alanine aminotransferase. One case of hereditary hypofibrinogenemia, one case of hereditary factor XI deficiency and one case of von Willebrand factor deficiency confirmed by laboratory examination were also excluded. Thus, 1375 infants and children were eligible for this study. We also enrolled 697 adult subjects to serve as a control group. The procedures that were performed on the study subjects are summarized in Table 1. Demographic features of the study cohort are shown in Table 2.

\section{Evolvement of APTT values with age}

APTT values showed a distinctive pattern of change in childhood (Table 2, Figure 1A). APTT values in neonates were longest, followed by infants aged 1-6 months. APTT values in infants aged 6-12 months were significantly shorter than those in infants aged 1-6 months $(p=0.000)$, approaching adult values but statistically different from adult values $(p=0.017)$. The hemostatic system changed gradually with increases in age. No significant differences were found between APTT values in children aged 1-2 years and adults $(p>0.05)$. However, APTT values showed a tendency for prolongation, significant differences being found 
Table 1 Minor elective surgeries performed on the study population.

\begin{tabular}{lcc}
\hline & $\begin{array}{c}\text { Infants and } \\
\text { children, } \mathrm{n}\end{array}$ & $\begin{array}{c}\text { Adult control } \\
\text { subjects, } \mathrm{n}\end{array}$ \\
\hline Circumcision & 201 & \\
$\begin{array}{l}\text { Adenotonsillectomy } \\
\text { Surgical treatments or }\end{array}$ & 161 & \\
plastic surgery for & & \\
$\quad$ Nasal septal deviation & 19 & 201 \\
Rhinopolypus & 19 & 135 \\
Scar & 131 & 46 \\
Pigmented naevus & 53 & 14 \\
Sebaceous cyst & 34 & 31 \\
Varicocele & 51 & 139 \\
Polydactyly & 98 & \\
Cutaneous hemangioma & 84 & \\
Cryptorchidism & 80 & \\
Hydrocele & 62 & \\
Cleft lip and palate & 64 & \\
$\quad$ Inguinal hernia & 45 & 131 \\
Other minor elective & 273 & \\
operations & & \\
\hline Total & 1375 & 697 \\
\hline
\end{tabular}

in children aged 3 years $(p=0.034)$ and aged 4-8 years $(p=0.000)$ when compared with adults. Starting at 9 years of age, APTT values shortened gradually, and approached adult levels by age 18 . However, these values were still different from those seen in adults $(p=0.038)$.

Comparison of APTT values in children at different ages showed that no significant differences were found in children aged 6 months to 3 years, $4-8$ years and 9-18 years, respectively. Thus, data in these age groups were combined for statistical analysis. The mean APTT value in the group of children 6 months to 3 years of age, consisting of 237 infants and children, was 38.10 (29.58-48.74) s; 4-8 years group, 390 children, 39.82 (31.20-49.32) s; and 9-18 years group, 699 children, $38.67(30.40-46.78)$ s. APTT values in all three combined groups were significantly longer than those seen in the adult control group $(p<0.001)$. Changes in APTT values following combining of groups is illustrated in Figure 1B.

\section{Lower FXII and FIX, and presence of LAC contributing to the prolongation of APTT values in children}

To explore the causes of prolongation of APTT values in children, PPP from 47 children with prolonged APTT value and PPP from 34 adult controls were collected between March 2007 and October 2007 (Table 3). FVIII:C, FIX:C, FXI:C, FXII:C and LAC were measured in batches after thawing of PPP. The results showed that FXII:C and FIX:C were significantly lower in PPP from children compared with controls $(p=0.000)$. FVIII:C and FXI:C were not significantly different between the two groups $(p=0.709$ and 0.280 , respectively) (Table 3 ). Although the mean LAC-SR seemed higher in PPP from children compared with controls, the difference was not statistically significant $(p=0.073)$. Although five LAC Confirm positive cases $(10.6 \%)$ were found in PPP from children and none in controls, no significant difference existed between

Table 2 APTT values in healthy Chinese neonates, infants and children aged 1-18 years compared with adults.

\begin{tabular}{|c|c|c|}
\hline Age & $\mathrm{n}$ (males/females) & APTT, s \\
\hline \multicolumn{3}{|c|}{ Neonates and infants } \\
\hline $1-30$ days $^{i}$ & $18(11 / 7)$ & $48.09(35.90-63.55)^{d}$ \\
\hline $1-6$ months $^{i}$ & $31(17 / 14)$ & $45.53(36.30-62.4)^{d}$ \\
\hline 6-12 months ${ }^{i}$ & $18(10 / 8)$ & $39.43(29.30-50.10)^{b, e, f}$ \\
\hline \multicolumn{3}{|l|}{ Children, years } \\
\hline 1 & $66(46 / 20)$ & $37.90(29.49-50.16)^{\mathrm{a}, \mathrm{f}}$ \\
\hline 2 & $78(55 / 23)$ & $37.69(28.78-46.41)^{\mathrm{a}, \mathrm{f}}$ \\
\hline 3 & $75(54 / 21)$ & $38.39(29.50-51.17)^{\mathrm{b}, \mathrm{f}}$ \\
\hline 4 & $78(58 / 20)$ & $39.96(29.79-49.37)^{\mathrm{d}, \mathrm{g}}$ \\
\hline 5 & $101(66 / 35)$ & $39.10(32.44-47.95)^{\mathrm{d}, \mathrm{g}}$ \\
\hline 6 & $76(56 / 20)$ & $40.24(32.01-50.40)^{\mathrm{d}, \mathrm{g}}$ \\
\hline 7 & $78(59 / 19)$ & $39.98(28.03-51.85)^{\mathrm{d}, \mathrm{g}}$ \\
\hline 8 & $57(45 / 12)$ & $40.15(31.56-52.82)^{\mathrm{d}, \mathrm{g}}$ \\
\hline 9 & $66(52 / 14)$ & $38.50(32.12-48.38)^{\mathrm{c}, \mathrm{h}}$ \\
\hline 10 & $73(48 / 25)$ & $38.33(29.11-47.31)^{\mathrm{b}, \mathrm{h}}$ \\
\hline 11 & $64(43 / 21)$ & $39.32(32.18-49.91)^{\mathrm{d}, \mathrm{h}}$ \\
\hline 12 & $65(41 / 24)$ & $39.17(30.11-52.18)^{\mathrm{c}, \mathrm{h}}$ \\
\hline 13 & $67(42 / 25)$ & $39.20(30.44-49.20)^{\mathrm{d}, \mathrm{h}}$ \\
\hline 14 & $63(46 / 17)$ & $38.79(28.78-47.23)^{\mathrm{c}, \mathrm{h}}$ \\
\hline 15 & $61(33 / 28)$ & $38.94(30.82-46.12)^{\mathrm{d}, \mathrm{h}}$ \\
\hline 16 & $76(37 / 39)$ & $38.70(27.10-46.86)^{\mathrm{d}, \mathrm{h}}$ \\
\hline 17 & $64(36 / 28)$ & $38.29(30.58-45.91)^{\mathrm{b}, \mathrm{h}}$ \\
\hline 18 & $100(46 / 54)$ & $37.89(29.02-47.37)^{\mathrm{b}, \mathrm{h}}$ \\
\hline Adults ${ }^{i}$ & $697(443 / 254)$ & $36.91(29.19-44.43)$ \\
\hline
\end{tabular}

APTT values are expressed as mean with 2.5th-97.5th percentile in parentheses. Compared with adults, APTT values are: insignificantly different ( $\left.{ }^{a} p>0.05\right)$; significantly prolonged ( $\left.{ }^{b} 0.01<p<0.05,{ }^{c} 0.001<p<0.01,{ }^{d} p=0.000\right)$. Compared with neonates and infants aged 1-6 months, APTT values are significantly shortened ( $\left.{ }^{e} p=0.000\right)$. Intergroup comparison, APTT values are insignificantly different $(\mathrm{f}, \mathrm{g}, \mathrm{h} p>0.05)$. 'The average ages of the four groups were $7.2 \pm 5.4$ days, $4.4 \pm 1.3$ months, $8.6 \pm 1.1$ months and $31.06 \pm 8.09$ years, respectively. 

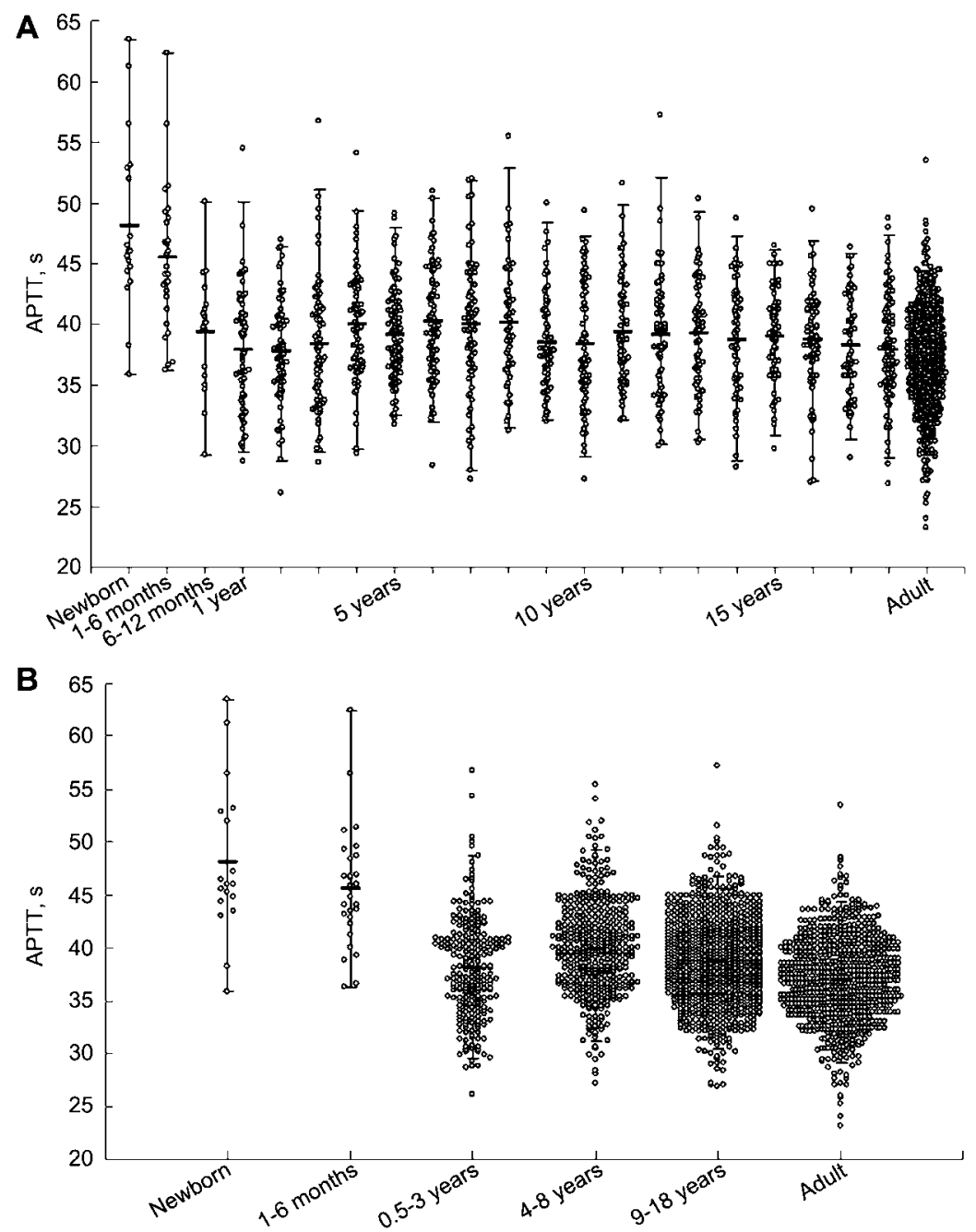

Figure 1 Age-associated changes in APTT values in healthy Chinese children. Each bar represents the mean with 2.5th-97.5th percentile.

(A) Distribution of APTT values in healthy Chinese neonates, infants and children aged 1-18 years. (B) Distribution of APTT values in healthy Chinese neonates, infants and children after data of no significant differences in different age groups being combined.

Table 3 Coagulation factor activities and LAC in children with prolonged APTT and adult control subjects.

\begin{tabular}{llll}
\hline & Children & Adults & p-Value \\
\hline $\mathrm{n}$ (males/females) & $47(33 / 14)$ & $34(23 / 11)$ & \\
Age, years & $4.54 \pm 4.46$ & $34.21 \pm 6.29$ & 0.000 \\
APTT, s & $45.27 \pm 2.12$ & $35.66 \pm 2.61$ & 0.280 \\
FVIII:C, $\%$ & $86.49 \pm 24.60$ & $81.13 \pm 17.43$ & 0.000 \\
FIX:C, $\%$ & $75.52 \pm 13.60$ & $98.59 \pm 12.16$ & 0.709 \\
FXI:C, $\%$ & $95.99 \pm 19.21$ & $97.49 \pm 15.58$ & 0.000 \\
FXII:C, $\%$ & $46.92 \pm 8.36$ & $86.59 \pm 23.95$ & 0.073 \\
LAC-SR & $1.03 \pm 0.10$ & $1.00 \pm 0.07$ & 0.071 \\
LAC Confirm positive & $5,10.6$ & 0,0 & \\
cases and positive rate, \% & & & \\
\hline
\end{tabular}

Data are expressed as mean $\pm 1 \mathrm{SD}$.

the two groups $(p=0.071)$. The prolonged APTT values correlated negatively with FXII:C, FIX:C and weakly with LAC-SR $\left(r_{0.01}=-0.808,-0.705\right.$ and 0.372 , $\mathrm{p}=0.000,0.000$ and 0.001 , respectively) (Figure 2). There was weak negative correlation between FXII:C and LAC-SR ( $r_{0.01}=-0.277, p=0.012$, data not shown). No significant correlation was found between prolonged APTT values and FVIII:C or FXI:C. The relationship between APTT and coagulation factors and LAC analyzed with stepwise multiple linear regression could be expressed as follows:

$$
\begin{aligned}
\operatorname{APTT}(\mathrm{s})= & 49.193-0.116 \text { FXII:C }(\%)-0.116 \text { FIX:C (\%) } \\
& +9.166 \text { LAC-SR, } r^{2}=0.771
\end{aligned}
$$

The above results indicated that lower concentrations of FXII:C and FIX:C, and the presence of LAC 

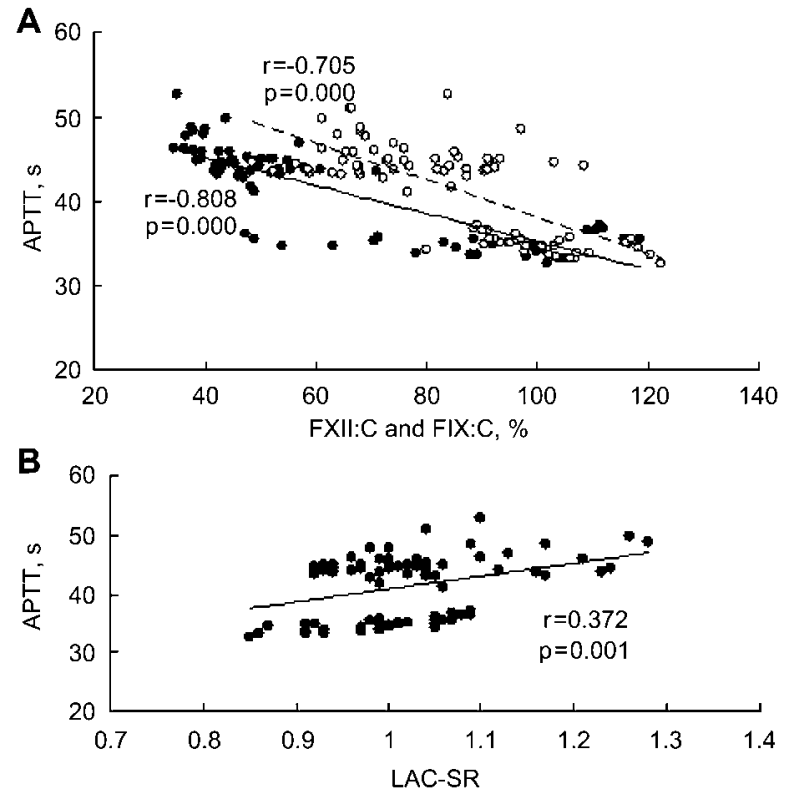

Figure 2 Correlation of APTT with FXII:C, FIX:C and LAC-SR. The study population is described in Table 3.

(A) APTT values correlated negatively with FXII:C $(0,-)$ and FIX:C $(O,---)$. (B) APTT values correlated weakly with LAC-SR.

contributed to the prolongation of APTT values in Chinese children.

\section{Discussion}

The hemostatic system evolves in a manner that is age-dependent $(5,8)$. Plasma concentrations of most pro- and anticoagulant proteins are decreased throughout childhood. However, they provide effective hemostatic balance at a lower level compared with adults $(5,6)$. This situation necessitates the generation of several appropriate age-dependent reference ranges to interpret laboratory data in pediatric patients and prevent misclassification of children having defects of factors and inhibitors of the coagulation system (7). Since there are differences in the hemostatic system among different racial/ethnic groups (10-27), and also between different analyzer and reagent systems (4), coagulation laboratories should develop age-related reference ranges specific to their own testing systems for the local population $(4,7,32)$. In this study, we analyzed retrospectively the results of preoperative APTT testing in childhood and adult controls undergoing minor elective surgery. We evaluated age-dependent development and maturation of the intrinsic coagulation system in healthy Chinese children. Our results showed that APTT values evolved with age and displayed a distinctive pattern of development in childhood. This confirms the concept of developmental hemostasis as elucidated by Andrew et al. (1-3). Due to different analyzer and reagent systems used, comparison of numerical differences in APTT values in children in this study with studies on other children (1-6, 8, 9, 29-31) is inappropriate. The adult APTT normal range in this study $(29.19-44.43 \mathrm{~s})$ is longer than that in Caucasian adults
(24.6-36.0 s) (33) when the same analyzer and reagent systems were used.

The prolonged APTT values in neonates could be explained by markedly decreased plasma concentrations of the vitamin K-dependent factors $(1,8,34)$ and contact factors, and partially by insufficient ratios of plasma to citrate caused by higher hematocrits (35). APTT values were also markedly prolonged in infants aged 1-6 months, which could be due to the hemostatic system of infants $<6$ months of age not being fully mature $(6,7)$. However, as healthy full-term neonates and infants aged 1-6 months who undergo minor elective operations in our hospital are uncommon, this study cannot elucidate in detail the changes in APTT values on different days following birth, which was one limitation of this study.

Near-adult values are achieved for most coagulation components by 6 months of age $(1,3)$. APTT values in infants aged 6-12 months were significantly shortened compared with infants aged 1-6 months $(p=0.000)$ and approximated adult values. No significant differences were found between APTT values in children aged $1-2$ years and adults $(p>0.05)$. This finding could be explained by development of the hemostatic system with age. Interestingly, APTT values showed a tendency for prolongation with significant differences seen in children 3 years of age $(p=0.034)$ and $4-8$ years of age $(p=0.000)$ compared with adults. From 9 years of age, APTT values gradually shortened, which could be ascribed to maturation of the hemostatic system.

Prolongation of the APTT is commonly due to decreased levels of contact factors (XI, XII, prekalikrein, high molecular weight kininogen), factors VIII and IX, and the presence of $\operatorname{LAC}(28,31,36)$. During the neonatal period, only low titers of factor XII appear to contribute significantly to the abnormal prolongation in APTT, while relative deficiencies of prekalikrein and high molecular weight kininogen usually do not have such effects (37). Our results suggest that decreased concentrations of FXII:C and FIX:C, and the presence of LAC contributed to the prolongation of APTT values in children. This differs slightly from the conclusion of Gallistl et al. (31) about causes for prolongation of the APTT in healthy Caucasian children. These authors suggest that APTT prolongation is caused by the combination of slightly lower clotting factors (VIII, IX, XII and HMWK). However, several studies $(1,6,8,37)$ have shown that the plasma factor VIII level in children was similar to that of adults, and even reached adult values at birth. Decreased levels of FXII:C and FIX:C in children in this study are consistent with the results of Monagle et al. (4), Andrew et al. (6) and Gallistl et al. (31). Low factor $\mathrm{XII}$ is a common finding in otherwise normal individuals $(28,36,38)$. This finding accounted for nearly half $(7 / 16)$ of the prolonged APTT values seen in a healthy Austrian population (38). Plasma factor XII activity concentrations in Orientals are lower than those seen in Caucasians due to higher allele frequency of frequently occurring $\mathrm{C}-->\mathrm{T}$ polymorphism in the factor XII promoter region at nucleotide (nt) 46 (25-27). This could partially explain the contribution of a markedly 
decreased FXII:C to prolongation of the APTT in healthy Chinese children.

The prevalence of transient and asymptomatic antiphospholipid antibodies (aPL) and/or LAC are more common in children than in adults (39-44), which can be partly ascribed to acquired infections (39-48). Since children suffer from infections more often than adults, this might explain why children had a much higher prevalence for LAC than adults (42), especially in early childhood $(43,44)$. Male et al. (43) reported that the prevalence of LAC in children peaked at 5 years of age. Similarly, Currimbhoy (44) found a significantly higher prevalence of LAC positivity not associated with symptoms in children younger than 12 years of age compared with older children $(3.1 \%$ vs. $0.5 \%)$. This may partially explain the age-associated phenomenon that APTT values displayed a tendency for prolongation in children after the age of 3 years, and gradually shortened after 9 years.

A frequent association of transient aPL and/or LAC with low factor XII exists $(45,48,49)$. This suggests that aPL and/or LAC play a role in the pathogenesis of decreased factor XII in children. However, no correlation between clotting tests indicative of LAC and aPL (42), and no correlation of increased APTT with abnormal thromboplastin inhibition or increased aPL (31) were observed. During childhood, LAC may be transient, and the longest persistent feature is a prolongation of clotting tests, even when aPL and phospholipid-dependent tests are no longer positive $(43,47)$. LAC-SR correlated weakly with FXII:C and APTT in this study, suggesting that decreased FXII:C concentrations caused by LAC do not play a key role in the mechanisms of APTT prolongation in children.

Our results show a distinct developmental pattern of age-related APTT values and causes of APTT prolongation in otherwise healthy Chinese children. These data will be helpful for accurate diagnosis and management of neonates and children with suspected bleeding or clotting disorders. Although routine coagulation testing to predict postoperative bleeding risk in unselected patients prior to surgery or other invasive procedures is not recommended $(36,50)$, our results combined with bleeding scores from structured clinical histories $(36,50)$ should reduce investigation of otherwise healthy Chinese children who are found to have mildly increased APTT values compared with adults, where routine coagulation tests are performed according to regulations.

\section{Conflict of interest statement}

We have not accepted any funding or support from an organization that may in any way gain or lose financially from the results of our study or the conclusions of our review. We have not been employed by an organization that may in any way gain or lose financially from the results of our study or the conclusions of our review. We have no potential conflicts of interest.

\section{Acknowledgements}

This work was supported in part by Scientific and Technologic Program of Healthy Bureau in Shenzhen City, China (No. 200609).

\section{References}

1. Andrew M, Paes B, Milner R, Johnston M, Mitchell L, Tollefsen DM, et al. Development of the human coagulation system in the full-term infant. Blood 1987;70: 165-72.

2. Andrew M, Paes B, Milner R, Johnston M, Mitchell L, Tollefsen DM, et al. Development of the human coagulation system in the healthy premature infant. Blood 1988;72:1651-7.

3. Andrew M, Paes B, Johnston M. Development of the hemostatic system in the neonate and young infant. Am J Pediatr Hematol Oncol 1990;12:95-104.

4. Monagle $P$, Barnes $C$, Ignjatovic V, Furmedge J, Newall F, Chan A, et al. Developmental haemostasis: impact for clinical haemostasis laboratories. Thromb Haemost 2006;95:362-72.

5. Kuhle S, Male C, Mitchell L. Developmental hemostasis: pro- and anticoagulant systems during childhood. Semin Thromb Hemost 2003;29:329-38.

6. Andrew M, Vegh $\mathrm{P}$, Johnston M, Bowker J, Ofosu F, Mitchell L. Maturation of the hemostatic system during childhood. Blood 1992;80:1998-2005.

7. Lippi G, Franchini M, Montagnana M, Guidi GC. Coagulation testing in pediatric patients: the young are not just miniature adults. Semin Thromb Hemost 2007;33:81620.

8. Andrew M. The relevance of developmental hemostasis to hemorrhagic disorders of newborns. Semin Perinatol 1997;21:70-85.

9. Lippi G, Salvagno GL, Rugolotto S, Chiaffoni GP, Padovani EM, Franchini $M$, et al. Routine coagulation tests in newborn and young infants. J Thromb Thrombolysis 2007;24:153-5.

10. White $\mathrm{RH}$, Zhou H, Romano PS. Incidence of idiopathic deep venous thrombosis and secondary thromboembolism among ethnic groups in California. Ann Intern Med 1998;128:737-40.

11. White $\mathrm{RH}$. The epidemiology of venous thromboembolism. Circulation 2003;107(Suppl 1):14-8.

12. Stein PD, Kayali F, Olson RE, Milford CE. Pulmonary thromboembolism in Asians/Pacific Islanders in the United States: analysis of data from the National Hospital Discharge Survey and the United States Bureau of the Census. Am J Med 2004;116:435-42.

13. White RH, Zhou H, Murin S, Harvey D. Effect of ethnicity and gender on the incidence of venous thromboembolism in a diverse population in California in 1996. Thromb Haemost 2005;93:298-305.

14. Keenan $\mathrm{CR}$, White $\mathrm{RH}$. The effects of race/ethnicity and sex on the risk of venous thromboembolism. Curr Opin Pulm Med 2007;13:377-83.

15. Cheuk BL, Cheung GC, Cheng SW. Epidemiology of venous thromboembolism in a Chinese population. $\mathrm{Br} \mathrm{J}$ Surg 2004;91:424-8.

16. Ridker PM, Miletich JP, Hennekens $\mathrm{CH}$, Buring JE. Ethnic distribution of factor $\mathrm{V}$ Leiden in 4047 men and women. Implications for venous thromboembolism screening. J Am Med Assoc 1997;277:1305-7.

17. Gregg JP, Yamane AJ, Grody WW. Prevalence of the factor V-Leiden mutation in four distinct American ethnic populations. Am J Med Genet 1997;73:334-6.

18. Rosendaal FR, Doggen CJ, Zivelin A, Arruda VR, Aiach $M$, Siscovick DS, et al. Geographic distribution of the $20210 \mathrm{G}$ to A prothrombin variant. Thromb Haemost 1998;79:706-8.

19. Zama T, Murata M, Ono F, Watanabe K, Watanabe R, Moriki $T$, et al. Low prevalence of activated protein $C$ resistance and coagulation factor V Arg506 to GIn mutation among Japanese patients with various forms of thrombosis, and normal individuals. Int J Hematol 1996; 65:71-8. 
20. Seki T, Okayama H, Kumagai T, Kumasaka N, Sakuma $\mathrm{M}$, Isoyama S, et al. Arg506GIn mutation of the coagulation factor $\mathrm{V}$ gene not detected in Japanese pulmonary thromboembolism. Heart Vessels 1998;13:195-8.

21. Lu Y, Zhao Y, Liu G, Wang X, Liu Z, Chen B, et al. Factor $V$ gene G1691A mutation, prothrombin gene $G 20210 A$ mutation, and MTHFR gene C677T mutation are not risk factors for pulmonary thromboembolism in Chinese population. Thromb Res 2002;106:7-12.

22. Jun ZJ, Ping T, Lei Y, Li L, Ming SY, Jing W. Prevalence of factor $V$ Leiden and prothrombin G20210A mutations in Chinese patients with deep venous thrombosis and pulmonary embolism. Clin Lab Haematol 2006;28:111-6.

23. Iso $H$, Folsom AR, Wu KK, Finch A, Munger RG, Sato $S$, et al. Hemostatic variables in Japanese and Caucasian men. Plasma fibrinogen, factor VIlc, factor VIIlc, and von Willebrand factor and their relations to cardiovascular disease risk factors. Am J Epidemiol 1989;130:925-34.

24. Lutsey PL, Cushman M, Steffen LM, Green D, Barr RG, Herrington D, et al. Plasma hemostatic factors and endothelial markers in four racial/ethnic groups: the MESA study. J Thromb Haemost 2006;4:2629-35.

25. Kanaji T, Okamura T, Osaki K, Kuroiwa M, Shimoda K, Hamasaki $N$, et al. A common genetic polymorphism (46 $\mathrm{C}$ to $\mathrm{T}$ substitution) in the $5^{\prime}$-untranslated region of the coagulation factor XII gene is associated with low translation efficiency and decrease in plasma factor XII level. Blood 1998;91:2010-4.

26. Endler G, Exner M, Mannhalter C, Meier S, Ruzicka K, Handler S, et al. A common C-- $>$ T polymorphism at nt 46 in the promoter region of coagulation factor $\mathrm{XII}$ is associated with decreased factor XII activity. Thromb Res 2001;101:255-60.

27. Gordon EM, Donaldson VH, Saito H, Su E, Ratnoff OD. Reduced titers of Hageman factor (factor XII) in Orientals. Ann Intern Med 1981;95:697-700.

28. Lippi G, Favaloro EJ. Activated partial thromboplastin time: new tricks for an old dogma. Semin Thromb Hemost 2008;34:604-11.

29. Flanders MM, Crist RA, Roberts WL, Rodgers GM. Pediatric reference intervals for seven common coagulation assays. Clin Chem 2005;51:1738-42.

30. Muntean W, Finding K, Leschnik B. Partial thromboplastin times are longer in healthy children than in adults. Thromb Haemorrh Disorders 1992;6:23-5.

31. Gallistl S, Muntean W, Leschnik B, Meyers W. Longer aPTT values in healthy children than in adults: no single cause. Thromb Res 1997;88:355-9.

32. Horowitz GL, Altaie S, Boyd JC, Ceriotti F, Garg U, Horn $P$, et al. Defining, establishing, and verifying reference intervals in the clinical laboratory; Approved Guideline. 3rd ed. Wayne, PA: Clinical and Laboratory Standards Institute (CLSI), 2008: CLSI document C28-A3; Vol. 28, No. 30.

33. http://www.il-italia.it/businessline/emostasi/pdf_emostasi/ INS_EN_0008468710.pdf.

34. Andrew M. Developmental hemostasis: relevance to hemostatic problems during childhood. Semin Thromb Hemost 1995;21:341-56.

35. Cerneca F, de Vonderweid U, Simeone R, Forleo V. The importance of hematocrit in the interpretation of coag- ulation tests in the full-term newborn infant. Haematologica 1994;79:25-8.

36. Watson HG, Greaves M. Can we predict bleeding? Semin Thromb Hemost 2008;34:97-103.

37. Gordon EM, Ratnoff OD, Saito H, Gross S, Jones PK. Studies on some coagulation factors (Hageman factor, plasma prekallikrein, and high molecular weight kininogen) in the normal newborn. Am J Pediatr Hematol Oncol 1980;2:213-6.

38. Halbmayer WM, Haushofer A, Schön R, Mannhalter C, Strohmer E, Baumgarten K, et al. The prevalence of moderate and severe FXII (Hageman factor) deficiency among the normal population: evaluation of the incidence of FXII deficiency among 300 healthy blood donors. Thromb Haemost 1994;71:68-72.

39. Hunt BJ. Pediatric antiphospholipid antibodies and antiphospholipid syndrome. Semin Thromb Hemost 2008;34:274-81.

40. Mizumoto H, Maihara T, Hiejima E, Shiota M, Hata A, Seto S, et al. Transient antiphospholipid antibodies associated with acute infections in children: a report of three cases and a review of the literature. Eur J Pediatr 2006;165:484-8.

41. Frauenknecht K, Lackner K, von Landenberg P. Antiphospholipid antibodies in pediatric patients with prolonged activated partial thromboplastin time during infection. Immunobiology 2005;210:799-805.

42. Siemens HJ, Gutsche $S$, Brückner $S$, Bucsky $P$, Katus HA. Antiphospholipid antibodies in children without and in adults with and without thrombophilia. Thromb Res 2000;98:241-7.

43. Male C, Lechner K, Eichinger S, Kyrle PA, Kapiotis S, Wank $\mathrm{H}$, et al. Clinical significance of lupus anticoagulants in children. J Pediatr 1999;134:199-205.

44. Currimbhoy Z. Transitory anticoagulants in healthy children. Am J Pediatr Hematol Oncol 1984;6:210-2.

45. Jaeger U, Kapiotis S, Pabinger I, Puchhammer E, Kyrle PA, Lechner K. Transient lupus anticoagulant associated with hypoprothrombinemia and factor XII deficiency following adenovirus infection. Ann Hematol 1993;67:95-9.

46. Shiomou K, Galanakis E, Tzoufi M, Tsaousi C, Papadopoulou ZL. Transient lupus anticoagulant and prolonged activated partial thromboplastin time secondary to Epstein-Barr virus infection. Scand J Infect Dis 2002; 34:67-9.

47. Male C, Lechner K, Speiser W, Pabinger I. Transient lupus anticoagulants in children: stepwise disappearance of diagnostic features. Thromb Haemost 2000;83: 174-5.

48. Aguilar Franco C, Cuesta JL. Antiphospholipid antibodies in asymptomatic pediatric patients. An Esp Pediatr 2001;54:444-9.

49. Edlinger G, Gallistl S, Muntean W. Lupus anticoagulant and factor XII activity in children with prolonged PTT. Thromb Res 1996;83:403-4.

50. Chee YL, Crawford JC, Watson HG, Greaves M. Guidelines on the assessment of bleeding risk prior to surgery or invasive procedures. British Committee for Standards in Haematology. Br J Haematol 2008;140:496-504. 